\title{
Peri-operative management of antiplatelet therapy in patients with coronary artery disease
}

\author{
Joint position paper by members of the working group on Perioperative Haemostasis of the \\ Society on Thrombosis and Haemostasis Research (GTH), the working group on Perioperative \\ Coagulation of the Austrian Society for Anesthesiology, Resuscitation and Intensive Care \\ (ÖGARI) and the Working Group Thrombosis of the European Society for Cardiology (ESC)
}

\author{
Wolfgang Korte'; Marco Cattaneo2; Pierre-Guy Chassot ${ }^{3}$; Sabine Eichinger"; Christian von Heymann ${ }^{5}$; Niklaus Hofmann ${ }^{6}$; \\ Hans Rickli'; Michael Spannagl ${ }^{8}$; Bernhard Ziegler ${ }^{9}$; Freek Verheugt ${ }^{10}$; Kurt Huber ${ }^{11}$ \\ ${ }^{1}$ Center for Laboratory Medicine, Kantonsspital St. Gallen, Switzerland; ${ }^{2}$ Medicina 3, Ospedale San Paolo, Department of Medicine, Surgery and Dentistry, \\ Università degli Studi di Milano, Milan, Italy; ${ }^{3}$ Departement of Anesthesiology, University Hospital Lausanne, Switzerland; ${ }^{4}$ Department of Medicine I, Division of Hematology, \\ Medical University of Vienna, Austria; ${ }^{5}$ Department of Anesthesiology and Intensive Care, Charité-Universitätsmedizin Berlin, Germany; ${ }^{6}$ Department of Anesthesiology, \\ Diakonissen-Krankenhaus Salzburg, Austria; ${ }^{7}$ Division of Cardiology, Kantonsspital St. Gallen, Switzerland; ${ }^{8}$ Division of Haemostaseology, University of Munich, Germany; \\ ${ }^{9}$ Department of Anesthesiology, Landeskliniken Salzburg, Austria; ${ }^{10}$ Department of Cardiology, Onze Lieve Vrouwe Gasthuis, Amsterdam, The Netherlands; ${ }^{11} 3^{\text {rd }}$ Medical \\ Department, Cardiology and Emergency Medicine, Wilhelminenspital, Vienna, Austria
}

\begin{abstract}
Summary
An increasing number of patients suffering from cardiovascular disease, especially coronary artery disease (CAD), are treated with aspirin and/or clopidogrel for the prevention of major adverse events. Unfortunately, there are no specific, widely accepted recommendations for the perioperative management of patients receiving antiplatelet therapy. Therefore, members of the Perioperative Haemostasis Group of the Society on Thrombosis and Haemostasis Research (GTH), the Perioperative Coagulation Group of the Austrian Society for Anesthesiology, Reanimation and Intensive Care (ÖGARI) and the Working Group Thrombosis of the European Society of Cardiology (ESC) have created this consensus position paper to provide clear recommendations on the perioperative use of anti-platelet agents (specifically with semi-urgent and urgent surgery), strongly supporting a multidisciplinary approach to optimize the treatment of individual patients with coronary artery disease who need major cardiac and non-cardiac surgery. With planned
\end{abstract}

Correspondence to:

PD Dr. Wolfgang Korte

Center for Laboratory Medicine

Kantonsspital St. Gallen

CH-9007 St. Gallen, Switzerland

Tel.: +41 7149439 33, Fax: +41 714943900

E-mail: wolfgang.korte@ikch.ch surgery, drug eluting stents (DES) should not be used unless surgery can be delayed for $\geq 12$ months after DES implantation. If surgery cannot be delayed, surgical revascularisation, bare-metal stents or pure balloon angioplasty should be considered. During ongoing antiplatelet therapy, elective surgery should be delayed for the recommended duration of treatment. In patients with semi-urgent surgery, the decision to prematurely stop one or both antiplatelet agents (at least 5 days pre-operatively) has to be taken after multidisciplinary consultation, evaluating the individual thrombotic and bleeding risk. Urgently needed surgery has to take place under full antiplatelet therapy despite the increased bleeding risk. A multidisciplinary approach for optimal antithrombotic and haemostatic patient management is thus mandatory.

\section{Keywords}

Antiplatelet agents, surgery, atherothrombosis, coronary syndrome, atherosclerosis

Financial support:

The meeting that allowed this manuscript to be formulated was supported by sanofi aventis (suisse) sa (a manufacturer of clopidogrel and enoxaparin). However, sanofi aventis had no influence whatsoever on the contents of this mansucript.

Received: April 7, 2010

Accepted after major revision: January 28, 2011

Prepublished online: March 24, 2011

doi:10.1160/TH10-04-0217

Thromb Haemost 2011; 105: 743-749

\section{Introduction}

An increasing number of patients who are suffering from or are at risk for cardiovascular disease, especially coronary artery disease $(\mathrm{CAD})$, is treated with aspirin or clopidogrel for the prevention of major adverse events. In congruence, the number of patients that receive percutaneous coronary intervention (PCI) with stent implantation continues to increase and therefore, the need for treatment with dual antiplatelet therapy (usually aspirin plus clopido- grel) is also augmented. In addition, an increased use of new and possibly more effective antiplatelet agents, e.g. prasugrel or ticagrelor, can be expected in the near future $(1,2)$. At present, $6-8 \%$ of patients with dual antiplatelet therapy also need oral anticoagulation with vitamin K antagonists (VKA) due to atrial fibrillation, mechanical heart valves or a history of venous thromboembolism. Given these facts, physicians nowadays face situations in which the peri-operative bleeding risk has to be balanced against the individual risk of thrombotic complications. Although the pathophysiol- 
ogy underlying peri-operative cardiovascular events remains to be completely elucidated, it is well known that inflammatory, hypercoagulable and hypoxic states are associated with plaque instability and peri-operative arterial thrombosis. Increased coronary shear stress after stress hormone release can lead to consecutive platelet activation, thus further adding to the risk for acute coronary thrombosis (3). On the other hand, platelet inhibition reduces inflammatory marker expression (4).

These considerations highlight that peri-operative platelet inhibition may prevent cardiovascular events, especially CADrelated events. Unfortunately, there are no specific, widely accepted recommendations for the peri-operative management of patients receiving antiplatelet therapy.

Accordingly, the authors, all experts in cardiology, anesthesiology and haematology as well as members of three different working groups from three different societies, have written this position paper, based on the available evidence.

\section{Antiplatelet therapy in patients at risk for or with known cardiovascular disease}

\section{Bleeding risk of antiplatelet therapy in the peri-interventional setting}

Most studies and meta-analyses describe an increased risk of perioperative blood loss and transfusions of blood products with the peri-operative use of aspirin (5-9), but one recent small trial suggests possible benefits (10). A large study in hip surgery found aspirin to reduce thromboembolic events but at a cost of a modest increase in bleeding complications (11). Bleeding complications in some types of surgery, e.g. dermatologic or ophthalmologic surgery (12), are usually not increased. In a meta-analysis, aspirin did not increase the severity of bleeding complications (with the exception of intracranial surgery and transurethral prostatectomy) but bleeding episodes were more frequent (13). It is unclear whether different aspirin doses might alter the frequency or the intensity of bleeding complications $(14,15)$.

The increased blood loss associated with peri-operative aspirin use in coronary artery bypass grafting with or without valve surgery can be counteracted by the use of antifibrinolytics (16); and first evidence exists from a very large, randomised and placebocontrolled trial that antifibrinolytic therapy is also beneficial in non-cardiac surgery patients with interventions such as trauma patients (17). Alternatively, it is likely that the use of platelet concentrates might lead to a similar effect, but there are no prospective trial data available and there is thus need for further research.

\section{Dual antiplatelet therapy and peri-operative bleeding risk}

Concerns on peri-operative bleeding still lead to premature discontinuation of antiplatelet therapy pre-operatively in daily prac- tice. However, despite the increased risk for oozing and diffuse haemorrhage, the transfusion rate in patients with or without dual antiplatelet therapy was not found to be significantly different in three different studies in general surgery (18-20). In contrast, significant increases in major bleeding (odds ratio [OR] 1.8; 95\% confidence interval [CI] $1.1-3.0$ ) and and re-operation (OR 4.6; $95 \%$ CI $1.4-14.5$ ) were seen in patients with acute coronary syndromes (ACS) requiring coronary artery bypass graft (CABG) with cardiopulmonary bypass (21). Excess major bleeding (without or with CABG $[22,23]$ ) and blood product use (in patients undergoing $\mathrm{CABG}[6,23]$ ) were also demonstrated if clopidogrel was not stopped at least five days before the intervention. On the other hand, no significant increase of bleeding complications was described despite continuation of dual antiplatelet therapy in patients with ACS and off-pump bypass surgery (24); this might therefore be a preferred method of surgical therapy in this very specific patient population on dual antiplatelet therapy. However, if additional thromboprophylaxis is given in patients undergoing various cardiosurgical procedures while on continuous mono- or dual antiplatelet therapy, an increased periprocedural bleeding risk is to be observed $(25,26)$.

As mentioned above, the peri-operative bleeding risk is related to the type of surgery: minor surgical interventions like dental procedures, cataract surgery, dermatologic operations, as well as angiographic diagnostic procedures or diagnostic endoscopies can apparently be performed under full anti-platelet therapy if no additional bleeding risks exist. A clear increase in haemorrhagic risk with dual antiplatelet therapy, however, has to be acknowledged in vascular, visceral and transbronchial surgery (27-29).

In patients on dual antiplatelet therapy undergoing any type of semi-urgent or urgent surgery, stopping antiplatelet therapy will not reduce platelet inhibition in a timely manner and multidisciplinary preparations for potential haemorrhagic complications should be undertaken. The pharmacokinetics of the respective platelet inhibitor used should be taken into consideration if platelet transfusion is planned.

\section{Primary prophylaxis}

Observations suggesting a preventive effect of aspirin on the occurrence of cardiovascular disease date back to the 1970s (30). The Physician's Health Study reported a highly significant $44 \%$ reduction in the risk of myocardial infarction (MI) for aspirin users along with a two-fold increased risk of haemorrhagic stroke, but no reduction in overall cardiovascular mortality or first time occurrence of angina (31). Risk reduction for MI occurred primarily in patients 50 years and older, but a risk increase for gastric ulcers and the need for blood transfusions was also seen (32). A cohort study in nurses confirmed the risk reduction for MI with primary prophylaxis in women (33).

The Thrombosis Prevention Trial was performed in a general practitioner's setting and evaluated aspirin and/or VKA (placebo controlled) for primary prevention of ischaemic heart disease (coronary death plus MI). Warfarin (all arms) reduced ischaemic heart disease by $21 \%$, mainly by reducing fatal events. Aspirin (all arms) 
reduced ischaemic heart disease by $20 \%$, almost entirely by reducing non-fatal events. The combination of warfarin and aspirin reduced ischaemic heart disease by $34 \%$ compared to placebo alone, but also increased haemorrhagic and fatal strokes (34). A recent review of the literature suggests that primary prevention with aspirin reduces the risk for $\mathrm{MI}$ in men and stroke in women, while increasing the risk for (predominantly gastrointestinal) serious bleeding events; aspirin in primary prevention does not seem to affect cardiovascular mortality or all-cause mortality in either men or women (35).

Benefits of aspirin use for primary prevention are not equally distributed but depend on various patient characteristics, e.g. the degree of the vasculopathic process (36) and the presence of hypertension $(37)$ or diabetes $(38,39)$. A certain prothrombotic effect through cyclooxygenase-2 inhibition after aspirin withdrawal has recently been postulated (40). Moreover, primary prevention data for aspirin from one country might not be easily applied to other countries, as shown for the US and Japan (41). And the peri-operative use of aspirin is associated with an increased bleeding risk (see above). Therefore, there are insufficient data supporting the efficacy and safety of antiplatelet drugs for primary prevention $(42,43)$. A large randomised controlled trial, currently underway, will hopefully help to answer the question on platelet inhibition for the primary prevention of cardiovascular events (44).

Given the above data, primary prevention with aspirin seems to have its place in patients with identifiable risk factors for cardiovascular disease, while at the same time the peri-operative use of aspirin is associated with increased bleeding hazards. Therefore, the US Preventive Services Task Force recommends to use aspirin for primary prophylaxis only in men between 45 and 80 years of age for MI prevention and in women between 55 and 80 years of age for stroke prevention $(35,45)$.

As the peri-operative use of aspirin is associated with increased blood loss and blood product use and as patients undergoing primary prophylaxis show no manifestation of any cardiovascular disease, this expert group suggests that aspirin given for primary prevention should be stopped 5-7 days before any type of surgery $(46,47)$. Further trials are required in order to confirm or refute this recommendation in the future.

\section{Secondary prophylaxis}

The German-Austrian Study Group has shown many years ago in a placebo-controlled prospective trial that platelet inhibition with high-dose aspirin (1,500 mg/day) as compared to oral anticoagulation is of benefit to prevent recurrent MI, specifically in male patients (48). A double-blind randomised trial with aspirin or placebo in patients with stable angina showed a clear benefit for the prevention of MI and sudden death (49). Moreover, a subgroup analysis from the Physician's Health Study showed a similar benefit of aspirin on the progression of CAD in patients with stable angina (50).

In line with these observations, an extensive meta-analysis on discontinuation or non-adherence to aspirin therapy indicated an increased risk for cardiovascular events (OR 3.1,95\% CI 1.7 - 5.6), especially in patients undergoing PCI with stent implantation (OR 89.8, 95\% CI 29.9-269.6) (51).
Data from a registry suggest that a considerable proportion of patients leaving the hospital after a MI have not received aspirin in the past, which in turn was associated with a high degree of cardiovascular morbidity and mortality within one year of follow-up (52).

Based on these data from trials and meta-analyses, aspirin or clopidogrel monotherapy (53) have favourable effects in preventing major adverse events in secondary prophylaxis of CAD; at the same time, the peri-operative bleeding rate and blood loss are increased in coronary bypass and orthopaedic surgery $(5-8,11)$. Interpretation of data on clopidogrel monotherapy in non-cardiac surgery is not trivial due to the small cohort sizes, heterogeneity of procedures, and absence of clear control groups (54).

In summary, there is likely a favourable peri-operative benefit-torisk profile for antiplatelet monotherapy (aspirin or clopidogrel) in secondary prevention with the exception of specific types of surgery and situations where the additional bleeding implies an important risk to the patient.

This expert group therefore recommends the continuation of aspirin (or clopidogrel) monotherapy for secondary prevention during most types of surgery. Only in patients undergoing surgical procedures in areas of closed space (e.g. intracranial neurosurgery, posterior chamber of the eye, medullary canal etc.) or when major bleeding complications are to be expected, stopping monotherapy with aspirin or clopidogrel 5-7 days pre-operatively should be evaluated on a case by case basis. Further clinical trials are warranted.

\section{Dual antiplatelet therapy following stent implantation in stable coronary artery disease and in acute coronary syndromes}

The guidelines of international cardiologic societies (ACC/AHA and ESC) (55-58) recommend dual antiplatelet therapy for a period of four (to six) weeks in patients undergoing elective PCI with bare-metal stents (BMS); 12 months are recommended when drug-eluting stents (DES) are used. Twelve months of dual antiplatelet therapy are also recommended after ACS, i.e. non ST-elevation myocardial infarction (NSTEMI) and ST-elevation myocardial infarction (STEMI), no matter which type of therapy was applied (conservative treatment, reperfusion therapy with PCI \pm stenting, or pharmacologic reperfusion with thrombolytic agents); the optimal duration of antiplatelet therapy is still under discussion and investigation $(59,60)$.

\section{"Triple" antithrombotic therapy following stent implantation}

The working group on thrombosis of the European Society of Cardiology (ESC) together with the European Heart Rhythm Association (EHRA) and the European Association of Percutaneous Cardiovascular Interventions (EAPCI) has recently commented on the management of antithrombotic therapy in atrial fibrillation patients after stent implantation, who need both, dual antiplatelet therapy and anticoagulation (61). The authors advocate a restrict- 
ive use of DES in patients who require anticoagulation with VKA i.e. patients with atrial fibrillation and a $\mathrm{CHADS}_{2}$ (Cardiac Failure, Hypertension, Age, Diabetes, Stroke [doubled] $_{\text {) }}$ score (62) of $>1$. "Triple" therapy is recommended for different time intervals based on the type of stent used and the individual risk of the patient for thrombotic and bleeding complications; this "triple“ therapy is then followed by combined antithrombotic treatment (VKA plus aspirin or clopidogrel) for up to 12 months. Most importantly, if VKA is combined with clopidogrel and/or aspirin, the target international normalized ratio (INR) should be $2.0-2.5$, with careful monitoring in short time intervals (41).

\section{Risk of premature discontinuation of antiplatelet therapy and overall thrombotic risk after coronary stenting}

Although reasons for the development of stent thrombosis are multifactorial, premature discontinuation of antiplatelet therapy has been found to be the most important risk factor after implantation of BMS (54) as well as DES (63). Surgical interventions were the reason for premature discontinuation of therapy in about $30-40 \%$ of patients (63). In patients with coronary stents and a variety of elective non-cardiac surgery within one year of stenting, the major adverse event rate was very high (45\%) and mainly due to cardiac events. This was despite the fact that patients were continued on or only very briefly interrupted ( $<3$ days before surgery) antiplatelet therapy plus regular peri-operative venous thromboprophylaxis with heparins; the risk for adverse events doubled if surgery was performed less than 35 days after stenting (64). Besides early discontinuation of dual antiplatelet therapy, different clinical and angiographic factors contribute to an increased risk for the development of stent thrombosis: advanced age, co-morbidities like diabetes, renal dysfunction, low ejection fraction, and ACS; coronary stenting in specific situations like multiple lesions, long lesions, bifurcations and ostial lesions; suboptimal stent deployment and overlapping stents (58). In addition, a reduced response to clopidogrel therapy is an important predictor of adverse outcome including stent thrombosis (65-67), suggesting that individualised therapy using specific devices might be advantageous (68-71).

\section{Recommendations regarding premature discontinuation of antiplatelet therapy}

Based on the subsequent risk of stent thrombosis and its potential consequences (MI, cardiovascular death) after premature discontinuation of antiplatelet therapy, especially in patients with DES, the ACC/AHA Science Advisory Panel recommends a) to avoid DES in patients likely not to comply with 12 months of thienopyridine therapy; b) that patients in need for elective surgery within 12 months of PCI be considered for BMS or balloon angioplasty; c) that patients be adequately informed and educated on the importance of thienopyridine therapy; d) that healthcare providers only discontinue antiplatelet therapy after discussion with the patients' cardiologist; e) that patients need to undergo a minimum of one month of thienopyridine treatment after BMS or 12 months after DES implantation; d) that aspirin be continued in patients with DES undergoing procedures that require discontinuation of thienopyridines; and that thienopyridines be restarted as soon as possible; and e) that drug costs should not lead to early discontinuation of thienopyridine therapy (72). Similar recommendations exist from other multidisciplinary boards (73).

Our group suggests that elective surgery be deferred until dual antiplatelet therapy is no longer necessary. In patients under dual antiplatelet therapy requiring closed space surgery (e.g. intracranial neurosurgery, posterior chamber of the eye, medullary canal) or other interventions associated with an increased haemorrhagic risk, stopping clopidogrel 5-7 days pre-operatively while continuing aspirin therapy should be considered. The group also suggests that short-term peri-operative venous thromboprophylaxis (unfractionated heparin or low-molecular-weight heparin [LMWH]) should only be started after the surgical procedure. If semi-urgent or urgent surgery is necessary, potential haemorrhagic complications and therefore the potential need for the respective management and therapy (such as multidisciplinary consulting, platelet transfusion and/or other procoagulant interventions, monitoring in a critical care environment, possibility for onsite cardiovascular intervention or transfer etc.) must be anticipated.

\section{Peri-operative "bridging" of antiplatelet therapy}

Neither unfractionated heparin nor LMWH can provide the antiplatelet effects associated with the use of clopidogrel and/or aspirin. If full antiplatelet therapy is required until the time of surgery but aspirin and/or clopidogrel cannot be used, the short-acting platelet antagonists eptifibatide (74) or tirofiban (75) might be considered up to a few hours before surgery as a „bridging“ therapy. These protocols have been successfully used in small patient series (75), but there is currently no controlled evidence to support their use. Therefore, future research should address the question how to best manage high-risk patients under antiplatelet therapy in the immediate peri-operative period.

\section{New antiplatelet drugs and new anticoagulants}

The European Medicines Agency (EMEA, EMA) approved prasugrel, a third generation thienopyridine, in late February 2009. The possible advantages of the irreversible adenosine diphosphate (ADP) receptor blocker prasugrel over clopidogrel include a faster onset of action, a more potent platelet inhibition (76), as well as less inter-individual variability of action of the agent. In patients with ACS and scheduled PCI, the use of prasugrel as compared to clopidogrel is associated with a lower event rate but a higher rate of clinically relevant bleeding (1). Ticagrelor is an oral, reversible and also more potent P2Y12 antagonist than clopidogrel and has shown better efficacy with a comparable overall major bleeding risk and a minor but significant increase in non-procedure-related 
Figure 1: Summary of the expert group's recommendation.

\begin{tabular}{|c|c|c|c|c|}
\hline $\begin{array}{l}\text { - extends also } \\
\text { to patients on } \\
\text { clopidogrel } \\
\text { monotherapy }\end{array}$ & \multicolumn{4}{|c|}{$\begin{array}{l}\text { Minor Surgery: do not stop antiplatelet therapy. } \\
\text { Implement mulitdisciplinary consult in patients with (potential) bleeding complications. } \\
\text { Low molecular weight heparin: NOT a substitute for platelet inhibiting drugs. } \\
\text { Avoid plasmatic anticoagulation (LMWH, OAC) during surgery. }\end{array}$} \\
\hline \multicolumn{2}{|c|}{ major surgery and } & how to proceed & exception & $\begin{array}{l}\text { how to proceed with } \\
\text { exception }\end{array}$ \\
\hline \multicolumn{2}{|c|}{$\begin{array}{l}\text { aspirin for primary } \\
\text { prevention }\end{array}$} & $\begin{array}{l}\text { stop aspirin } 5 \text { days } \\
\text { before surgery }\end{array}$ & & \\
\hline \multicolumn{2}{|c|}{$\begin{array}{l}\text { aspirin in high-risk } \\
\text { patients } \\
\text { (diabetes, history of } \mathrm{CV} \\
\text { events, documented } \mathrm{CV} \\
\text { disease, increased global risk) }\end{array}$} & continue aspirin ${ }^{*}$ & $\begin{array}{l}\text { surgery in } \\
\text { closed space, } \\
\text { expected major } \\
\text { bleeding } \\
\text { complications }\end{array}$ & $\begin{array}{l}\text { - stop aspirin } 5 \text { days before } \\
\text { surgery } \\
\text { - consider restarting within } 24 \mathrm{~h} \text { * }\end{array}$ \\
\hline \multicolumn{2}{|c|}{$\begin{array}{l}\text { aspirin plus clopidogrel in } \\
\text { high risk patients }\end{array}$} & $\begin{array}{l}\text { 1. elective surgery: } \\
\text { delay until no dual } \\
\text { inhibition necessary } \\
\text { 2. semi-urgent surgery: } \\
\text { continue aspirin } \pm \\
\text { clopidogrel on a case } \\
\text { by case basis } \\
\text { 3. urgent surgery } \\
\text { (within } 24 \mathrm{~h} \text { ): } \\
\text { continue aspirin and } \\
\text { clopidogrel }\end{array}$ & $\begin{array}{l}\text { surgery in } \\
\text { closed space, } \\
\text { expected major } \\
\text { bleeding } \\
\text { complications }\end{array}$ & $\begin{array}{l}\text { If delaying surgery not possible / } \\
\text { semi-urgent surgery necessary: } \\
\text { - stop clopidogrel } 5 \text { days before } \\
\text { surgery, consider bridging } \\
\text { (short acting GPIIb/llla } \\
\text { antagonist) } \\
\text { - consider stopping also aspirin in } \\
\text { particular patients } \\
\text { - consider resuming dual } \\
\text { antiplatelet therapy asap }\end{array}$ \\
\hline
\end{tabular}

bleeding, including more fatal intracranial bleeding episodes and fewer fatal bleeding episodes of other types (77). The agent might enter the market soon as it is currently under evaluation for approval by the FDA and the EMA. The appearance of further new antiplatelet (78) and other antithrombotic agents, i.e. direct inhibitors of factor Xa or thrombin and the respective indications for these new drugs will necessitate continued consideration and repeated updating of recommendations such as the ones presented here.

Our group emphasises a careful decision-making process of all involved relevant specialties in the pre-operative assessment phase for patients with coronary stents under dual antiplatelet therapy as indicated by international guidelines. However, the adherence to such guidelines is low (79) and our working group therefore re-emphasises the necessity of a multidisciplinary approach for the individual patient, mirrored by the different disciplines represented within our group.

\section{Conclusion}

Many treatment decisions have to be made in patients with CAD who need cardiac (such as on- and off-pump CABG or valve surgery) and non-cardiac surgery. The group believes that multidisciplinary discussions between cardiologists, anesthesiologists, hae- matologists and surgeons are needed to optimise the treatment of the individual patient.

Primary prophylaxis with antiplatelet drugs should be stopped five days ahead of surgery.

If PCI and stenting is performed, the use of DES should be avoided if surgery is necessary within 12 months of stent implantation. Instead, PCI and stenting with BMS, pure balloon angioplasty or CABG should be considered unless very specific situations make the use of a DES still more beneficial.

When the need for surgery becomes apparent during the time of recommended dual antiplatelet therapy (or triple therapy), surgery should be delayed for the whole time of recommended dual antiplatelet therapy in patients in whom it can be performed electively.

In patients in whom surgery is imminent or urgent, the operation has to take place under full antiplatelet therapy despite the increased bleeding risk. It should be kept in mind that an increased bleeding risk under dual antiplatelet therapy could turn into an acute thrombotic risk if measures to improve haemostasis are necessary to reduce the bleeding risk.

In patients with a semi-urgent operation, the decision to prematurely stop one or both antiplatelet agents (at least five days before surgery) has to be made in close cooperation of the different involved specialties, whereby the individual risk of thrombosis versus bleeding has to be carefully evaluated.

These recommendations are summarised in Figure 1. 


\section{References}

1. Wiviott SD, Braunwald E, McCabe CH, et al. Prasugrel versus clopidogrel in patients with acute coronary syndromes. N Engl J Med 2007; 357: 2001-2015.

2. Mahoney EM, Wang K, Arnold SV, et al. Cost-effectiveness of prasugrel versus clopidogrel in patients with acute coronary syndromes and planned percutaneous coronary intervention: results from the trial to assess improvement in therapeutic outcomes by optimizing platelet inhibition with Prasugrel-Thrombolysis in Myocardial Infarction TRITON-TIMI 38. Circulation 2010; 121:71-79.

3. Devereaux PJ, Goldman L, Yusuf S, et al. Surveillance and prevention of major perioperative ischemic cardiac events in patients undergoing noncardiac surgery: a review. CMAJ 2005; 173: 779-788.

4. Muhlestein JB. Effect of antiplatelet therapy on inflammatory markers in atherothrombotic patients. Thromb Haemost 2010; 103: 71-82.

5. Kallis P, Tooze JA, Talbot S, et al. Pre-operative aspirin decreases platelet aggregation and increases post-operative blood loss--a prospective, randomised, placebo controlled, double-blind clinical trial in 100 patients with chronic stable angina. Eur J Cardiothorac Surg 1994; 8: 404-409.

6. Ray JG, Deniz S, Olivieri A, et al. Increased blood product use among coronary artery bypass patients prescribed preoperative aspirin and clopidogrel. BMC Cardiovasc Disord 2003; 3: 3.

7. Alghamdi AA, Moussa F, Fremes SE. Does the use of preoperative aspirin increase the risk of bleeding in patients undergoing coronary artery bypass grafting surgery? Systematic review and meta-analysis. J Card Surg 2007; 22: 247-256.

8. Sun JC, Whitlock R, Cheng J, et al. The effect of pre-operative aspirin on bleeding, transfusion, myocardial infarction, and mortality in coronary artery bypass surgery: a systematic review of randomized and observational studies. Eur Heart 2008; 29: 1057-1071.

9. Anekstein Y, Tamir E, Halperin N, et al. Aspirin therapy and bleeding during proximal femoral fracture surgery. Clin Orthop Relat Res 2004; 418: 205-208.

10. Oscarsson A, Gupta A, Fredrikson M, et al. To continue or discontinue aspirin in the perioperative period: a randomized, controlled clinical trial. Br J Anaesth 2010; 104: 305-312.

11. Prevention of pulmonary embolism and deep vein thrombosis with low dose aspirin: Pulmonary Embolism Prevention (PEP) trial. Lancet 2000; 355: 1295-1302.

12. Narendran N, Williamson TH. The effects of aspirin and warfarin therapy on haemorrhage in vitreoretinal surgery. Acta Ophthalmol Scand 2003; 81: 38-40.

13. Burger W, Chemnitius JM, Kneissl GD, et al. Low-dose aspirin for secondary cardiovascular prevention - cardiovascular risks after its perioperative withdrawal versus bleeding risks with its continuation - review and meta-analysis. J Intern Med 2005; 257: 399-414.

14. Kong DF. Aspirin in cardiovascular disorders. What is the optimum dose? Am Cardiovasc Drugs 2004; 4: 151-158.

15. Fisher M, Knappertz V. The dose of aspirin for the prevention of cardiovascular and cerebrovascular events. Curr Med Res Opin 2006; 22: 1239-1248.

16. McIlroy DR, Myles PS, Phillips LE, et al. Antifibrinolytics in cardiac surgical patients receiving aspirin: a systematic review and meta-analysis. Br J Anaesth 2009 102: $168-178$.

17. Shakur H, Roberts I, Bautista R, et al. Effects of tranexamic acid on death, vascular occlusive events, and blood transfusion in trauma patients with significant haemorrhage (CRASH-2): a randomised, placebo-controlled trial. Lancet 2010 376: $23-32$.

18. Wilson SH, Fasseas P, Orford JL, et al. Clinical outcome of patients undergoing non-cardiac surgery in the two months following coronary stenting. J Am Coll Cardiol 2003; 42: 234-240.

19. Schouten O, van Domburg RT, Bax JJ, et al. Noncardiac surgery after coronary stenting: early surgery and interruption of antiplatelet therapy are associated with an increase in major adverse cardiac events. J Am Coll Cardiol 2007; 49: 122-124.

20. Rabbitts JA, Nuttall GA, Brown MJ, et al. Cardiac risk of noncardiac surgery after percutaneous coronary intervention with drug-eluting stents. Anesthesiology 2008; 109: 596-604.

21. Berger JS, Frye CB, Harshaw Q, et al. Impact of clopidogrel in patients with acute coronary syndromes requiring coronary artery bypass surgery: a multicenter analysis. J Am Coll Cardiol 2008; 52: 1693-1701.

22. Yusuf S, Zhao F, Mehta SR, et al. Effects of clopidogrel in addition to aspirin in patients with acute coronary syndromes without ST-segment elevation. N Engl J Med 2001; 345: 494-502.
23. Ebrahimi R, Dyke C, Mehran R, et al. Outcomes following pre-operative clopidogrel administration in patients with acute coronary syndromes undergoing coronary artery bypass surgery: the ACUITY (Acute Catheterization and Urgent Intervention Triage strategY) trial. J Am Coll Cardiol 2009; 53: 1965-1972.

24. Song SW, Youn YN, Yi G, et al. Effects of continuous administration of clopidogrel before off-pump coronary artery bypass grafting in patients with acute coronary syndrome. Circ J 2008; 72: 626-632.

25. McDonald SB, Renna M, Spitznagel EL, et al. Preoperative use of enoxaparin increases the risk of postoperative bleeding and re-exploration in cardiac surgery patients. J Cardiothorac Vasc Anesth 2005; 19: 4-10.

26. Jones HU, Muhlestein JB, Jones KW, et al. Early postoperative use of unfractionated heparin or enoxaparin is associated with increased surgical re-exploration for bleeding. Ann Thorac Surg 2005; 80: 518-522.

27. Chapman TW, Bowley DM, Lambert AW, et al. Haemorrhage associated with combined clopidogrel and aspirin therapy. Eur J Vasc Endovasc Surg 2001; 22: 478-479.

28. Moore M, Power M. Perioperative hemorrhage and combined clopidogrel and aspirin therapy. Anesthesiology 2004; 101: 792-794.

29. Ernst A, Eberhardt R, Wahidi M, et al. Effect of routine clopidogrel use on bleeding complications after transbronchial biopsy in humans. Chest 2006; 129: 734-737.

30. Linos A, Worthington JW, O'Fallon W, et al. Effect of aspirin on prevention of coronary and cerebrovascular disease in patients with rheumatoid arthritis. A longterm follow-up study. Mayo Clin Proc 1978; 53: 581-586.

31. Manson JE, Grobbee DE, Stampfer MJ, et al. Aspirin in the primary prevention of angina pectoris in a randomized trial of United States physicians. Am J Med 1990; 89: 772-776.

32. Final report on the aspirin component of the ongoing Physicians' Health Study. Steering Committee of the Physicians' Health Study Research Group. N Engl J Med 1989; 321: 129-135.

33. Manson JE, Stampfer MJ, Colditz GA, et al. A prospective study of aspirin use and primary prevention of cardiovascular disease in women. J Am Med Assoc 1991; 266: 521-527.

34. Thrombosis prevention trial: randomised trial of low-intensity oral anticoagulation with warfarin and low-dose aspirin in the primary prevention of ischaemic heart disease in men at increased risk. The Medical Research Council's General Practice Research Framework. Lancet 1998; 351: 233-241.

35. Wolff T, Miller T, Ko S. Aspirin for the primary prevention of cardiovascular events: an update of the evidence for the U.S. Preventive Services Task Force. Ann Intern Med 2009; 150: 405-410.

36. Fowkes FG, Price JF, Stewart MC, et al. Aspirin for prevention of cardiovascular events in a general population screened for a low ankle brachial index: a randomized controlled trial. J Am Med Assoc 2010; 303: 841-848.

37. Meade TW, Brennan PJ. Determination of who may derive most benefit from aspirin in primary prevention: subgroup results from a randomised controlled trial. Br Med J 2000; 321: 13-17.

38. De Berardis G, Sacco M, Strippoli GF, et al. Aspirin for primary prevention of cardiovascular events in people with diabetes: meta-analysis of randomised controlled trials. Br Med J 2009; 339: b4531.

39. Leung WY, So WY, Stewart D, et al. Lack of benefits for prevention of cardiovascular disease with aspirin therapy in type 2 diabetic patients--a longitudinal observational study. Cardiovasc Diabetol 2009; 8: 57.

40. Doutremepuich C, Aguejouf O, Desplat V, et al. Aspirin therapy: an attempt to explain the events of prothrombotic complications after treatment discontinuation. Thromb Haemost 2010; 103: 171-180.

41. Morimoto T, Fukui T, Lee TH, et al. Application of U.S. guidelines in other countries: aspirin for the primary prevention of cardiovascular events in Japan. Am J Med 2004; 117: 459-468.

42. Silagy CA, McNeil JJ, Donnan GA, et al. Adverse effects of low-dose aspirin in a healthy elderly population. Clin Pharmacol Ther 1993; 54: 84-89.

43. Nelson MR, Liew D, Bertram M, et al. Epidemiological modelling of routine use of low dose aspirin for the primary prevention of coronary heart disease and stroke in those aged $>$ or $=70$. Br Med J 2005; 330: 1306.

44. Nelson M, Reid C, Beilin L, et al. Rationale for a trial of low-dose aspirin for the primary prevention of major adverse cardiovascular events and vascular dementia in the elderly: Aspirin in Reducing Events in the Elderly (ASPREE). Drugs Aging 2003; 20: 897-903. 
45. Aspirin for the prevention of cardiovascular disease: U.S. Preventive Services Task Force recommendation statement. Ann Intern Med 2009; 150: 396-404.

46. Connor AM, Laposata M. A rapid assay for platelet thromboxane production and its use in assessing prior aspirin ingestion. Am J Clin Pathol 1988; 89: 216-221.

47. Cahill RA, McGreal GT, Crowe BH, et al. Duration of increased bleeding tendency after cessation of aspirin therapy. J Am Coll Surg 2005; 200: 564-573; quiz A59-61.

48. Breddin K, Loew D, Lechner K, et al. The German-Austrian aspirin trial: a comparison of acetylsalicylic acid, placebo and phenprocoumon in secondary prevention of myocardial infarction. On behalf of the German-Austrian Study Group. Circulation 1980; 62: V63-72.

49. Juul-Moller S, Edvardsson N, Jahnmatz B, et al. Double-blind trial of aspirin in primary prevention of myocardial infarction in patients with stable chronic angina pectoris. The Swedish Angina Pectoris Aspirin Trial (SAPAT) Group. Lancet 1992; 340: 1421-1425.

50. Ridker PM, Manson JE, Gaziano JM, et al. Low-dose aspirin therapy for chronic stable angina. A randomized, placebo-controlled clinical trial. Ann Intern Med 1991; 114: 835-839.

51. Biondi-Zoccai GG, Lotrionte M, Agostoni P, et al. A systematic review and metaanalysis on the hazards of discontinuing or not adhering to aspirin among 50,279 patients at risk for coronary artery disease. Eur Heart J 2006; 27: 2667-2674.

52. Frilling B, Schiele R, Gitt AK, et al. Too little aspirin for secondary prevention after acute myocardial infarction in patients at high risk for cardiovascular events: Results from the MITRA study. Am Heart J 2004; 148: 306-3011.

53. Algra A, van Gijn J. Is clopidogrel superior to aspirin in secondary prevention of vascular disease? Curr Control Trials Cardiovasc Med 2000; 1: 143-145.

54. Luckie M, Khattar RS, Fraser D. Non-cardiac surgery and antiplatelet therapy following coronary artery stenting. Heart 2009; 95: 1303-1308.

55. Van de Werf F, Bax J, Betriu A, et al. Management of acute myocardial infarction in patients presenting with persistent ST-segment elevation: the Task Force on the Management of ST-Segment Elevation Acute Myocardial Infarction of the European Society of Cardiology. Eur Heart J 2008; 29: 2909-2945.

56. Silber S, Albertsson P, Aviles FF, et al. Guidelines for percutaneous coronary interventions. The Task Force for Percutaneous Coronary Interventions of the European Society of Cardiology. Eur Heart J 2005; 26: 804-847.

57. Bassand JP, Hamm CW, Ardissino D, et al. Guidelines for the diagnosis and treatment of non-ST-segment elevation acute coronary syndromes. Eur Heart J 2007; 28: $1598-1660$.

58. Grines CL, Bonow RO, Casey DE, Jr., et al. Prevention of premature discontinuation of dual antiplatelet therapy in patients with coronary artery stents: a science advisory from the American Heart Association, American College of Cardiology, Society for Cardiovascular Angiography and Interventions, American College of Surgeons, and American Dental Association, with representation from the American College of Physicians. Circulation 2007; 115: 813-818.

59. Byrne RA, Schulz S, Mehilli J, et al. Rationale and design of a randomized, doubleblind, placebo-controlled trial of 6 versus 12 months clopidogrel therapy after implantation of a drug-eluting stent: The Intracoronary Stenting and Antithrombotic Regimen: Safety And EFficacy of 6 Months Dual Antiplatelet Therapy After Drug-Eluting Stenting (ISAR-SAFE) study. Am Heart J 2009; 157: 620-624 e2.

60. Park SJ, Park DW, Kim YH, et al. Duration of dual antiplatelet therapy after implantation of drug-eluting stents. N Engl J Med 2010; 362: 1374-1382.

61. Lip GY, Huber K, Andreotti F, et al. Management of antithrombotic therapy in atrial fibrillation patients presenting with acute coronary syndrome and/or undergoing percutaneous coronary intervention/ stenting. Thromb Haemost 2010; 103: 13-28.
62. Gage BF, Waterman AD, Shannon W, et al. Validation of clinical classification schemes for predicting stroke: results from the National Registry of Atrial Fibrillation. J Am Med Assoc 2001; 285: 2864-2870.

63. Iakovou I, Schmidt T, Bonizzoni E, et al. Incidence, predictors, and outcome of thrombosis after successful implantation of drug-eluting stents. J Am Med Assoc 2005; 293: 2126-2130.

64. Vicenzi MN, Meislitzer T, Heitzinger B, et al. Coronary artery stenting and noncardiac surgery--a prospective outcome study. Br J Anaesth 2006; 96: 686-693.

65. Campo G, Fileti L, Valgimigli M, et al. Poor response to clopidogrel: current and future options for its management. J Thromb Thrombolysis 2010; 30: 319-331.

66. Sofi F, Marcucci R, Gori AM, et al. Clopidogrel non-responsiveness and risk of cardiovascular morbidity. An updated meta-analysis. Thromb Haemost 2010; 103: $841-848$

67. Sibbing D, Morath T, Braun S, et al. Clopidogrel response status assessed with Multiplate point-of-care analysis and the incidence and timing of stent thrombosis over six months following coronary stenting. Thromb Haemost 2010; 103: 151-159.

68. Zurn CS, Geisler T, Gawaz M. ADP-receptor blockade: A case for personalised pharmacotherapy? Thromb Haemost 2010; 103: 496-506.

69. Bal Dit Sollier C, Berge N, Boval B, et al. Differential sensitivity and kinetics of response of different ex vivo tests monitoring functional variability of platelet response to clopidogrel. Thromb Haemost 2010; 104: 104: 571-581.

70. Siller-Matula JM, Gouya G, Wolzt M, et al. Cross validation of the Multiple Electrode Aggregometry. A prospective trial in healthy volunteers. Thromb Haemost 2009; 102: 397-403.

71. Gremmel T, Steiner S, Seidinger D, et al. Comparison of methods to evaluate clopidogrel-mediated platelet inhibition after percutaneous intervention with stent implantation. Thromb Haemost 2009; 101: 333-339.

72. Grines CL, Bonow RO, Casey DE, Jr., et al. Prevention of premature discontinuation of dual antiplatelet therapy in patients with coronary artery stents: a science advisory from the American Heart Association, American College of Cardiology, Society for Cardiovascular Angiography and Interventions, American College of Surgeons, and American Dental Association, with representation from the American College of Physicians. J Am Coll Cardiol 2007; 49: 734-739.

73. Albaladejo P, Marret E, Piriou V, et al. Perioperative management of antiplatelet agents in patients with coronary stents: recommendations of a French Task Force. Br J Anaesth 2006; 97: 580-582.

74. Wilczynski M, Bochenek T, Goral J, et al. [Bridging by eptifibatide on patients with acute stent thrombosis, requiring urgent surgical revascularisation - report of 2 cases.]. Kardiol Pol 2009; 67: 1313-1316.

75. Savonitto S, D'Urbano M, Caracciolo M, et al. Urgent surgery in patients with a recently implanted coronary drug-eluting stent: a phase II study of 'bridging' antiplatelet therapy with tirofiban during temporary withdrawal of clopidogrel. Br J Anaesth 2010; 104: 285-291.

76. Montalescot G, Sideris G, Cohen R, et al. Prasugrel compared with high-dose clopidogrel in acute coronary syndrome. The randomised, double-blind ACAPULCO study. Thromb Haemost 2010; 103: 213-223.

77. Wallentin L, Becker RC, Budaj A, et al. Ticagrelor versus clopidogrel in patients with acute coronary syndromes. N Engl J Med 2009; 361: 1045-1057.

78. Zafar MU, Ibanez B, Choi BG, et al. A new oral antiplatelet agent with potent antithrombotic properties: comparison of DZ-697b with clopidogrel a randomised phase I study. Thromb Haemost 2010; 103: 205-212.

79. Mukerji G, Munasinghe I, Raza A. A survey of the peri-operative management of urological patients on clopidogrel. Ann R Coll Surg Engl 2009; 91: 313-320. 